\title{
BIOLOGICAL IMPLICATIONS OF ORGANIC COMPOUNDS IN COMETS
}

\author{
JOSEPH N. MARCUS AND MARGARET A. OLSEN \\ Departments of Pathology and Medical Microbiology \\ Creighton University \\ Omaha, NE 68131, U.S.A.
}

\begin{abstract}
Organic chemicals - compounds that contain carbon - are the substance of life and pervade the universe. Is there a connection between comets, which are rich in prebiotic organics, and the origin of life? Current concepts of biomolecular evolution are first reviewed, including the important paradigm of catalytic RNA. At the very least, impacting comets appear to have supplied a substantial fraction of the volatile elements required for life shortly after the Earth formed. Some impacting material may even have survived chemically intact to directly provide necessary complex prebiotic organic chemicals. For life to originate and evolve in comets themselves, liquid $\mathrm{H}_{2} \mathrm{O}$ would be absolutely required: arguments for and against ${ }^{26} \mathrm{Al}$ radiogenic melting of cometary cores are presented. Cometary panspermia, if theoretically possible, is not necessary to explain the origin of life on Earth. The Halley spacecraft provide evidence against Earth-type microorganisms in this comet's dust.
\end{abstract}

\section{Introduction}

One of the real triumphs of the Halley reconnaissance spacecraft was clearly establishing that a large fraction of the comet was made of very complex organic chemicals, as had been strongly suspected previously. Inevitably, this fuels the question of how comets may be connected to the origin of life, which is made of the same or similar chemicals. To address this question comprehensively, we approach it from several angles in this chapter. First, the organic composition of comets, progenitor material, and the related carbonaceous chondrites is reviewed from a prebiotic and biological perspective. Next, we look at the new thinking on biomolecular evolution and the origin of life. For most of this century, this event has been envisaged as terrestrial, self-contained on the Earth's surface. However, the momentum is now great for a major, if not essential, contribution by infalling comets. In the concluding sections, we assess the variations on the theme of a cometary connection to the origin of life.

\section{The Organic Cosmos}

\subsection{THE INTERSTELLAR MEDIUM}

In the model of Greenberg (1982), comets are nearly primordial, low-temperature $(10 \mathrm{~K})$ condensates of star-forming dust and gas clouds in the interstellar medium. There is substantial evidence that a large fraction of this interstellar material is organic. 
2.1.1. Molecules. In the gas phase, of some 68 molecules identified in dense cloud regions, nearly three-quarters are organic (Oró and Berry, 1987). $\mathrm{CO}, \mathrm{H}_{2} \mathrm{O}$, and $\mathrm{H}_{2} \mathrm{CO}$ are among the most abundant species (Irvine and Hjalmarson, 1984); the largest molecule is the 13-atom cyano-decapenta-yne $\left(\mathrm{HC}_{11} \mathrm{~N}\right)$ (Bell et al., 1982). While methanimine and formic acid, the direct precursors of the simplest amino acid, glycine, have been identified, a direct search for interstellar glycine was negative (Snyder et al., 1983), and no interstellar amino acid has been identified to date. Nevertheless, there is good reason to believe that interstellar amino acids (or at least their precursors) must exist, as $\mathrm{D} / \mathrm{H}$ and ${ }^{15} \mathrm{~N} /{ }^{14} \mathrm{~N}$ isotopic signatures in those from carbonaceous chondrites indicate a probable interstellar origin (Epstein et al., 1987; Cronin, Pizzarello and Cruikshank, 1988).

2.1.2. Grains. In regard to the dust phase, about one-fifth appears to be comprised of nonvolatile organics (Greenberg, 1982). Wickramasinghe and Allen (1980) attribute the 3.4- $\mu \mathrm{m}$ absorption band in infrared (IR) sources to the stretching vibration of the $\mathrm{C}-\mathrm{H}$ bond in organic compounds, and attributed the $3.36-\mu \mathrm{m}$ and $3.48-\mu \mathrm{m}$ bands in a particularly resolved source to paraformaldehyde, the polymer of formaldehyde (Allen and Wickramasinghe, 1981), well before its discovery in comet Halley (Huebner, 1987; Mitchell et al., 1987). Indeed, a strong correlation between $\mathrm{H}_{2} \mathrm{CO}$ abundance at $4.83 \mathrm{GHz}$ and visual extinction has been noted, suggesting a depletion of $\mathrm{H}_{2} \mathrm{CO}$ on the absorbing grains (Minn and Greenberg, 1987). Nevertheless, because of the relatively low resolution of spectra in the 3- $\mu \mathrm{m}$ region, and the low specificity of given features for specific organic compounds, identification of specific species is difficult and a conservative approach is justified. Other organic compounds, particularly polycyclic aromatic hydrocarbons (PAHs), can account for features in this region (Leger and Puget, 1984), and undoubtably numerous different organic compounds must be present. The 220-nm ultraviolet (UV) absorption feature has been attributed to PAHs in small spherical particles (Hoyle and Wickramasinghe, 1977), while Greenberg (1987) attributes the feature more generally to non-graphitic, $0.01-\mu \mathrm{m}$-size linear chain unsaturated organic molecules.

2.1.3. Carbon Source. Interstellar carbon originates in the outflows of cool carbon stars. Kroto (1988) proposes that this carbon may be in the form of fullerenes, a particularly stable form of which is $\mathrm{C}_{60}$ (buckminsterfullerene), a closed icosahedral cage shaped like a soccer ball. These huge, complex molecules may be the starting material for the refractory carbon in interstellar grains and, by extension, comets. Rich in cyclic conjugated double bonds, the fullerenes are attractive candidates for interstellar reactions that may give rise to PAHs and the cyanopolyynes, and they could account for the Diffuse Interstellar Bands (Kroto, 1988). Support for Kroto's proposed interstellar fullerenes comes with the recently reported discovery of graphitic soot-like spherules in the Murchison $\mathrm{C} 2$ carbonaceous chondrite. Their primordial interstellar origins are indicated by their heterogeneous, strikingly non-solar ${ }^{12} \mathrm{C} /{ }^{13} \mathrm{C}$ ratios (Amari et al., 1990).

2.1.4. Irradiated Ices. In the laboratory, complex organic compounds form when ultra-cold simple precursor ices are irradiated with ultraviolet light or charged particles in chambers designed to simulate the conditions of grain surfaces in interstellar clouds (e.g., Sagan and Khare, 1979; Greenberg, 1982; Strazzulla, Calcagno and Foti, 1983; reviewed in Strazzulla and Johnson, 1990, this volume). The resulting photolysis generates free radicals, which may recombine immediately to form new, more complex molecules. Or they can remain immobilized because of the low temperature $(10 \mathrm{~K})$, but recombine during warmup, with attendant chemiluminescence in UV irradiation experiments (Greenberg, 1982). In these experiments, a significant fraction $(\approx 20 \%)$ ends up as a refractory, insoluable organic residue, leading to the prediction of a complex organic mantle surrounding silicate cores in the larger $(\approx 0.3 \mu \mathrm{m})$ interstellar grains (Greenberg, 1982). From UV irradiation of an initial mixture of $\mathrm{CO}, \mathrm{NH}_{3}, \mathrm{H}_{2} \mathrm{O}$ and $\mathrm{CH}_{4}$, quantities of $\mathrm{H}_{2} \mathrm{CO}$ 
comparable to the initial $\mathrm{H}_{2} \mathrm{O}$ and $\mathrm{NH}_{3}$ can be produced (Greenberg, 1984), along with more complex material suggestive of amino pyroline rings. UV irradiation of initial $\mathrm{CO} / \mathrm{NH}_{3} / \mathrm{H}_{2} \mathrm{O}$ mixtures generates such biotically or prebiotically significant molecules as urea, lactic acid, glyceric acid, and glycerol (Agarwal et al., 1985).

Chyba and Sagan (1989) comment that the fact that the UV dose on interstellar grains generally may be $10^{2}$ to $10^{3}$ that of low-energy cosmic rays is not necessarily decisive for the relative importance of the two agents in forming interstellar organics. In the absence of UV (as in optically thick clouds), low energy cosmic rays would still completely polymerize carbon-containing ices over the lifetime of a cloud. Greenberg et al. (1989), however, maintain a central role for UV.

\subsection{CARBONACEOUS CHONDRITES}

These meteorites are similar to comets in their relatively high (but lesser) carbon content ( $\approx 3 \%$ for the $\mathrm{C} 1$ class), and condensation from the solar nebula at cold (but relatively higher) temperatures. Their organic chemistry is quite complex (see Cronin et al. [1988] for a recent review). Most of the carbon is refractory, possibly consisting in part of relatively primordial PAHs of interstellar origin, based on deuterium enrichment (Cronin et al., 1988), and infrared spectral similarities (Wdowiak et al., 1989). Extractable classes of organic compounds include aliphatic hydrocarbons (> $35 \mathrm{ppm})$, aromatic hydrocarbons (15-28 ppm), mono- and di-carboxylic acids (>300 ppm, > $30 \mathrm{ppm})$, hydroxycarboxylic acids (15 ppm), basic nitrogen heterocycles $(7 \mathrm{ppm})$, amines (8 ppm), amides (55-70 ppm), alchohols (11 ppm), and aldehydes and ketones (27 ppm). These meteorites are especially remarkable for also containing building block molecules of life, listed in the following subsections.

2.2.1. Amino Acids. In the Murchison $\mathrm{CM} 2$ meteorite, amino acids are present at $60 \mathrm{ppm}$, with 74 different ones having been identified (Cronin et al., 1988). Nineteen occur on Earth biologically, eight of them as constituents of proteins. In studies that are best controlled for contamination of samples by terrestrial microorganisms, amino acids in carbonaceous chondrites are clearly abiogenic, as witnessed by their racemized states (equal concentrations of $D$ and $L$ enantiomers) (Bada et al., 1983), and the occurrence of forms not naturally found on Earth. It has been suggested that meteoric amino acids formed by Fischer-Tropsch or Miller-Urey syntheses (Cronin, Pizzarello and Cruikshank, 1988), or by aqueous alteration of matrix PAHs (Shock and Schulte, 1990). Peptides (amide-linked amino acids) also have tentatively been reported in the Murchison and two other carbonaceous chondrites (Ivanov et al., 1984).

2.2.2. Purines and Pyrimidines. In the Murchison, purine and pyrimidine bases total about $1.2 \mathrm{ppm}$. Amongst them, the biologic nucleic acid bases adenine, guanine, and uracil have been securely identified (Cronin, 1988), while the remaining common biologic bases, thymine and cytosine, have been reported provisionally (Hua et al., 1986).

2.2.3. Amphiphilic Compounds. Evaporated chloroform extracts of the Murchison meteorite contain lipid-like amphiphilic compounds that can self-assemble into 1- to 10- $\mu \mathrm{m}$-sized vesicles when mixed with water (Deamer, 1985). Mass spectroscopy shows that one fraction contains straight and branched chain alkanes from 13 to 23 carbons in length, which compares with the 12 or more present in biological lipid membranes. As a further striking similarity to biologic membranes, the meteorite-derived membranes display a trilaminar structure by electron microscopy (Deamer and Pashley 1989), as shown in Figure 1. 


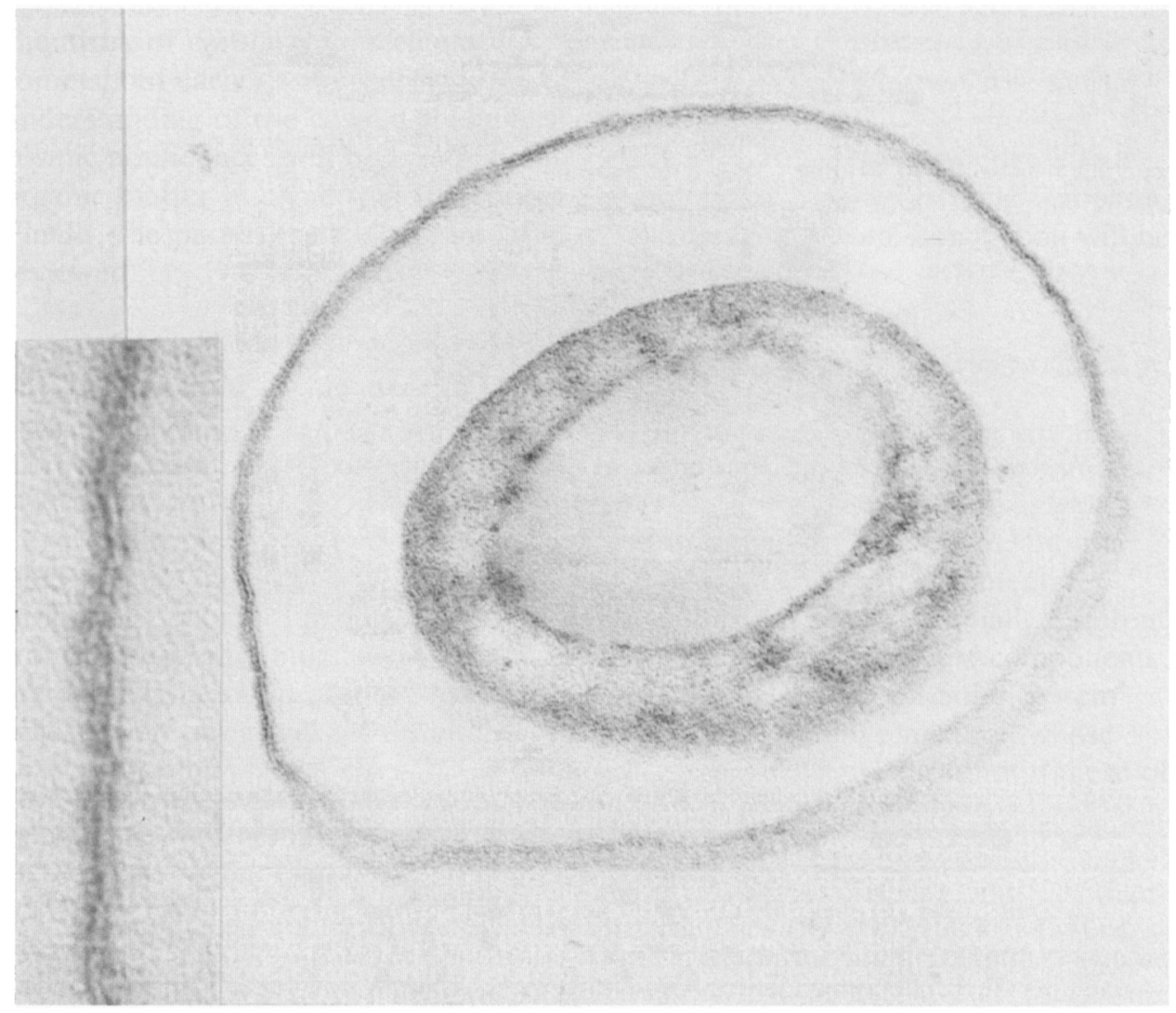

Figure 1. Amphiphilic organic material, chloroform-extracted from the Murchison C2 chondrite, spontaneously forms membrane-enclosed vesicles when water is added. Magnified inset shows a trilaminar membrane structure similar to that in lipid membranes of living cells. Courtesy Dr. David Deamer, U. California, Irvine.

\subsection{COMETS}

The organic composition of comets is extensively reviewed in this volume (1990; see particularly Encrenaz and Knacke; Delsemme; Jessberger; Johnstone and Kranowsky) and elsewhere (Clark, 1988). Here we highlight aspects that pertain to prebiotic chemistry.

2.3.1. Prebiotic Volatile Building Blocks. Hydrogen cyanide $(\mathrm{HCN})$ and formaldehyde $\left(\mathrm{H}_{2} \mathrm{CO}\right)$ are volatiles critical in prebiotic chemistry (Sec. 3.1.1). HCN has been detected in comets Kohoutek 1973 XII, P/Halley 1986 III, and, most recently, Austin 1989c1 (Bockelée-Morvan et al., 1990). While the detection of $\mathrm{H}_{2} \mathrm{CO}$ in P/Halley was tentative (Combes et al., 1988), its recent identification in Austin appears secure (Bockelee-Morvan et al., 1990). In Delsemme's (1990, this volume) model of comet Halley, $\mathrm{HCN}$ and $\mathrm{H}_{2} \mathrm{CO}$ abundances are, respectively, $1 \%$ and $4 \%$ to $5 \%$ that of $\mathrm{H}_{2} \mathrm{O}$, which comprises $\approx 80 \%$ of the comet's volatile fraction, and which is essential to life. 
2.3.2. Infrared Signature. The same 3.4- $\mu \mathrm{m} \mathrm{C-H}$ bond fluorescence emission seen in interstellar clouds has also been identified in comets Halley and Wilson and likewise attributed to complex non-volatile organic molecules (Encrenaz and Knacke, 1990, this volume).

2.3.3. CHON Particles. An important discovery of the VEGA and Giotto spacecraft, the fine dust containing various combinations of carbon, hydrogen, oxygen and nitrogen ("CHON") (Langevin et al., 1987) is a major repository of relatively non-volatile to refractory organics, which, from the data compiled in Delsemme (1990, this volume), can be estimated to be $\approx 20 \%$ of the mass of comet Halley. It is almost certainly the "distributed source" for the spiral $\mathrm{CN}, \mathrm{C}_{2}$, and $\mathrm{C}_{3}$ jets observed from Earth (A'Hearn et al., 1986; Cosmovici et al., 1988), and a "sink" for the "missing carbon" of comets pointed out by Delsemme (1982). Paraformaldehyde (polyoxymethylene), the first polymer to be discovered in space (Huebner, 1987; Mitchell et al., 1987), apparently resides in these grains, which serve as a distributed source for about half of the CO observed in P/Halley (Eberhardt et al., 1987). CHON particles are also the likely source of the recently identified aromatic, $\mathrm{C}_{3} \mathrm{H}_{3}{ }^{+}$(cyclopropenyl) (Korth et al., 1989), as well as the more complex organics described below.

2.3.4. Complex Organic Molecules. The VEGA 1 PUMA mass spectrometer provided evidence for the probable existence of many classes of cyclic and acyclic organic compounds in the Halley dust (Kissel and Krueger, 1987). Among the biologically more significant ones are adenine (the purine nucleic acid base), and pyrimidines and their derivatives. The failure to detect the biologically important $\alpha$-amino acids implies that they are at least 30 times less abundant than the purines and pyrimidines, a situation inverse to that of the carbonaceous chondrites (see above). Similarly, sugars appear to be in low abundance, judging by the lack of the expected breakdown product, $\mathrm{CH}_{2} \mathrm{OH}^{+}$, in the mass spectra (Kissel and Krueger, 1987).

2.3.5. The Amino Acid Problem. The apparent paucity (or absence) of $\alpha$-amino acids in Halley's comet (Kissel and Krueger, 1987) is puzzling on two counts. First, while some of the amino acids in carbonaceous chondrites may have been generated in the solar nebula through, e.g., FischerTropsch-type (FTT) synthesis from hot $\mathrm{CO}, \mathrm{H}_{2}$, and $\mathrm{NH}_{3}$ on $\mathrm{Fe}_{2} \mathrm{O}_{3}$ or clay catalysts (Cronin et al., 1988; Delsemme, 1990, this volume; see Sec. 2.2.1), it would appear reasonable that at least a fraction of them must have been synthesized in interstellar space, as evidenced by their non-solar $\mathrm{D} / \mathrm{H}$ and ${ }^{15} \mathrm{~N} /{ }^{14} \mathrm{~N}$ isotope ratios in the Murchison chondrite (Sec. 2.1.1). Since comets are thought to be more pristine relative to interstellar material than carbonaceous chondrites, amino acids should thus be expected. This expectation would be circumvented, however, if only the precursors of amino acids were synthesized in the interstellar medium. Second, there is some evidence that the non-terrestrial amino acid $\alpha$-amino isobutyric acid evidently identified near the 65-Myr-old Cretaceous-Tertiary $(\mathrm{K} / \mathrm{T})$ boundary may be of cometary origin (Zhao and Bada, 1989; see Sec. 4.2.4). Space does not allow detailed interpretation here of these somewhat disparate isotope, $\mathrm{K} / \mathrm{T}$, and VEGA 1 data sets. We merely remark that all of the evidence for and against amino acids in comets is to varying degrees indirect, model-dependent, and provisional, although at the present time, the VEGA 1 PUMA data should probably be given greater weight. If the PUMA data are correct (but see Sec. 4.2.4), no special problem is posed for the origin of life if this event depended on chemically intact cometary material (Sec. 4.2.3), since in the new paradigm, amino acids and proteins came later in biomolecular evolution (next section). 
3. The Origin of Life

\subsection{BIOMOLECULAR EVOLUTION}

Before proceeding to questions on the relation of comets to the origin of life, we briefly overview current concepts of biomolecular evolution, for such knowledge will, to some extent, guide and constrain our approach.

The past decade has brought major advances - indeed, a sea change - in our understanding. No longer is deoxyribonucleic acid (DNA) - a replicating set of genes commanding the production of proteins via messenger and transfer ribonucleic acids (RNAs: mRNA and tRNA) - seen as the first molecule of life. This scenario always had the discomfitting chicken-and-egg problem: did DNA come first, or did protein? Neither can function without the other. RNAs were servile minor actors that developed later: mRNA carried its complementary DNA "message" to ribosomes (complexes of protein and ribosomal RNA — rRNA), which assembled proteins from individual amino acids borne to them by tRNAs, according to the base sequence instructions in mRNA.

In the new paradigm, RNA comes to center stage, the result of the astonishing discovery that it can have enzymatic (specific catalytic) activity (Cech et al., 1986a). Hitherto, this function was thought to be exclusive to proteins, although catalytic RNA clearly had been predicted (Woese, 1967; Crick, 1968; Orgel, 1968). Its discovery was the subject of the 1989 Nobel Prize in chemistry (Waldrop, 1989), and the import for the origin of life is enormous. In just one molecule, there is now both the function of a gene (to bear information) and an enzyme (to catalyze chemical reactions, including the ability, in principle, to self-replicate). In the new thinking, RNA is ancestral to DNA and preceded proteins. It was one of the earliest living molecules.

What follows is a brief outline of the major steps in the origin and early evolution of life, as can best be inferred today. All of the steps are necessarily inferential and speculative, especially the earlier ones, and most of the proposed intermediary biomolecules do not survive today. A more detailed review can be found in Weiner (1987).

3.1.1. Prebiotic Chemistry. During this era, simple organic compounds condensed to form the monomer building blocks of the basic classes of oligomeric biomolecules (Miller, 1987). HCN and $\mathrm{H}_{2} \mathrm{CO}$ were important starting chemicals. Purines (e.g., adenine) condensed from $\mathrm{HCN}$, and pyrimidines (e.g., cytosine, uracil), from $\mathrm{HCN}$ and cyanoacetelyne $\left(\mathrm{HC}_{3} \mathrm{~N}\right)$. $\left(\mathrm{HCN}, \mathrm{H}_{2} \mathrm{CO}\right.$, purines and pyrimidines all are ubiquitous in Halley's comet - see Sec. 2.3.) Carbohydrate sugars likely condensed from $\mathrm{H}_{2} \mathrm{CO}$ in the formose reaction. $\mathrm{HCN}, \mathrm{NH}_{3}$, and aldehydes yielded amino acids by Strecker synthesis, and long-chain amphiphilic fatty acids could arise through Fischer-Tropsch-type (FTT) condensation of $\mathrm{H}_{2}$ and $\mathrm{CO}$.

Various of these reactions could have occurred at many different sites in the universe (Cronin, 1988): the Earth, the solar nebula, meteorite parent bodies, comets, or interstellar space. Whereas most opinion has hitherto favored Miller-Urey synthesis on Earth from $\mathrm{HCN}, \mathrm{H}_{2} \mathrm{CO}$, etc. (Miller, 1987), the Earth's early atmosphere may not have been sufficiently reducing, and these starting compounds may not have been present in sufficient quantity (see Sec. 4.2.2).

At this early stage, amphiphilic compounds, exceeding a critical concentration in water, may spontaneously have formed membranes that self-assembled into closed cell-like vesicles, analagous to the spontaneous behavior of the amphiphilic extracts from the Murchison chondrite (Sec. 2.2.3; Figure 1). These vesicles contained and concentrated prebiotic organic compounds and shielded them from deleterious effects of the external environment. Moreover, their membranes may have incorporated primitive pigments that photochemically helped establish energy gradients needed to drive catalysis and early metabolism (Weiner, 1987; Morowitz et al., 1988). 
Simple molecules like glycerol and glyceraldehyde may have functioned both in early metabolism and, in polymer form, for information storage (Weber, 1989).

3.1.2. Pre-RNA World. Mineral catalysis in clays likely facilitated some simple chemical reactions, such as the formation of phosphate ester bonds, important in metabolism and oligomerization of building blocks (Ferris, 1987). Indeed, phosphorylated nucleotide co-enzymes such as adenosine diphosphate glucose have recently been synthesized abiotically from simple precuorsors under simulated primitive Earth conditions (Mar and Or6, 1989). In particular, phosphate ester bonds would have joined nucleotides (phosphorylated sugar-linked pyrimidine or purine monomers) into primitive nucleic acid oligomers. These first nucleic acids of the pre-RNA world were almost certainly different from modern RNA and DNA.

With RNA now viewed as such a pivotal molecule in early life, special problems leading to its origin have been identified (Ferris, 1987). For one thing, the formose reaction leads to a wide variety of sugars, only a minute fraction of which is ribose, the one found in RNA, and what little is produced is unstable (Shapiro, 1988). For another, extension of growing oligonucleotide chains is inhibited when both D- and L-ribose forms are present, as would be expected during prebiotic conditions (Joyce, 1987). Chain elongation proceeds, however, when just the D or L form is present. This phenomenon, enantiomeric cross-inhibition, has been demonstrated with different templates and monomers in experiments involving template-driven condensation, in which a polynucleotide replicates by directing the polymerization of complementary monomers (Joyce et al., 1984). (Complementary hydrogen bonding, in the RNA world, occurs between the base pairs adenine-guanine and cytosine-uracil [cytosine-thymine in the DNA world]. This Watson-Crick base-pairing is central in DNA, RNA, and probably pre-RNA nucleic acid replication.)

These problems could be resolved if, instead of rigid-ring, chiral moieties like ribose, ancestral activated nucleosides contained some prochiral open-ring analog such as glycerol, acrolein, or erythritol (Orgel, 1987; Joyce et al., 1987). In the RNA analog shown in Figure 2, the glycerol moiety's acyclic, open-ring structure is more flexible, and would permit oligomerization on the template without chiral inhibition.

3.1.3. RNA World. The selection of D-ribose, and the modern nucleic acid bases (adenine, guanine, cytosine, uracil for RNA), heralded this era. The first RNA molecules may have replicated by simple template-driven condensation, possibly catalyzed by metal ions. Later, enzymatic activity mediated by the RNA itself (prompting the term "ribozyme" for catalytic RNA) and cofactors would have served to replicate RNA (Cech, 1986b). In other words, RNA became its own template. While such catalytic replicating RNA evidently no longer exists in nature, experimental support for it comes in the recent synthesis of an artificial ribozyme able to catalyze the ligation of short oligonucleotides, resulting in a complementary copy of the original RNA template (Doudna and Szostak, 1989).

Thus, packed into one molecule - RNA - is both information storage and catalysis, central qualities of living matter. Orgel (1987) has suggested that pre-RNA nucleic acids may even have had catalytic activity. If any of these catalyzed the synthesis of D-ribose, the transition from the pre-RNA to RNA world would have been facilitated.

RNA would have catalyzed many other types of chemical reactions important to metabolism. Thus, membrane-enclosed "cells" or "protocells" (Sec. 3.1.1) could accumulate scarce molecules, and assemble more complicated structures than would be possible in the more primitive external environment. Ribozymes would be expected to evolve ever more sophisticated functions, a notion experimentally supported in the recent mutation, selection, and amplification of RNA for specialized catalytic functions (Robertson and Joyce, 1990). 


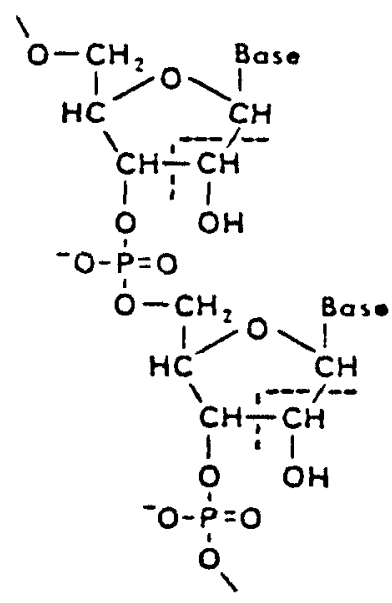

RNA<smiles></smiles>

GLYCEROL ANALOGUE

Figure 2. RNA contains the sugar ribose as a connecting unit in the polymer (left). However, other simpler and more available units, such as glycerol, may have substituted in ancestral nucleic acid polymers (right). From Orgel (1987).

3.1.4. RNP World. $\alpha$-, $\beta$-, and $\gamma$-amino acids, racemized in $\mathrm{D}$ and $\mathrm{L}$ forms, are ubiquitous extraterrestrially (Secs. 2.2.1 and 2.3.5) and easily synthesized in simulated prebiotic conditions (Miller, 1987). However, only some 20 members of the $\alpha$ subclass, and only the L enantiomer forms, were selected as the monomeric units of proteins, whose appearance as catalysts ("enzymes") heralded the ribonucleoprotein (RNP) world.

Protein enzymes brought much more versatility and specificity to catalysis than ribozymes. Their synthesis, however, required a complicated translation apparatus that must have evolved slowly over a period of time. To accomplish this, RNA evolved into three functional species, mRNA, tRNA, and rRNA, described above. This period marked the origin of the "genetic code," the triplet base sequences in mRNA that directed, via tRNA and rRNA, the placement of corresponding amino acids in the extending protein chain in the ribosome. In time, special enzymes to replicate RNA, the RNA polymerases, evolved.

At this stage, genetic information probably would have been organized into separate RNA molecule "minigenes" (Gilbert, 1987). These encoded small peptides, which would have assembled with others to form active enzymatic complexes. Soon, the corresponding RNA minigenes combined to form larger genes coding for proteins that had the enzymatic activity on their own. In this way, larger and larger RNA strands were built. This ability to splice and shuffle minigenes to make different proteins would have greatly speeded evolution.

3.1.5. DNA World. To make DNA required several new enzymes: ribonucleotide reductase (to make deoxyribose from ribose), thymidylate synthase (to make thymidine), and DNA polymerase (to replicate the DNA). The great advantage of DNA over RNA is its genetic stability against mutations, which was even further enhanced with the appearance of DNA "repair" enzymes. The replication "error rate" is $10^{-8}$ to $10^{-12}$ per incorporated nucleotide for DNA, compared with $10^{-4}$ for RNA, and $10^{-1}$ to $10^{-2}$ for template-driven condensation (Lazcano et al., 1988). 
Just when DNA came into existence in the biomolecular scheme of things has become controversial. Rather than the scenario outlined here, Benner et al. (1989) propose that DNA was present in the RNA world for genetic information storage and emerged before proteins.

3.1.6. Moder World. By now, we are quite late into evolution for our purposes. A "last common ancestor," or progenote, likely preceded the nearly simultaneous divergence of DNA Earth life into three basic kingdoms, the archaebacteria, the eubacteria, and the eukaryotes (Woese, 1987) some 2.3 to perhaps 3.5-3.8 Gyr ago (see the next section). Later, mitochondria and chloroplasts extranuclear, energy-producing organelles of bacterial origin - were incorporated endosymbiotically into the cytoplasm of various eukaryote lineages (Figure 3 ). While photosynthesis is very ancient (see the next section), wholesale movement toward an oxygen-rich atmosphere did not begin until about 2.0 to 2.5 Gyr ago, and was not complete until about 1.7 Gyr ago (Walker et al., 1983). The first plant and animal fossils appeared only a scant $0.6-0.7 \mathrm{Gyr}$ ago!

\subsection{THE GREAT ANTIQUITY OF EARTH LIFE}

Several independent lines of evidence, some quite recent, indicate that life in the form of microorganisms was present on the Earth virtually as soon as the planet had formed and devastating impacts (Sec. 4.2.6) had subsided.

3.2.1. Chert Microfossils. The carboniferous cherts are among the oldest rocks on the Earth's surface. Those from the Swaziland system in South Africa date to 3.4-3.5 Gyr before present (b.p.) and contain algae-like, 1- to 4- $\mu \mathrm{m}$ organic walled structures, many in various stages of binary fission, that have been interpreted as microfossils (Knoll and Barghoorn, 1977). Woese (1987) interprets these as photosynthetic bacteria. The Isua quartzite from Greenland is $3.8 \mathrm{Gyr}$ old and has similar microstructures (Pflug, 1984a), although their identification as fossil microorganisms is less secure.

3.2.2. Carbon Isotope Signature. Photosynthesis fractionates carbon isotopes so that ${ }^{12} \mathrm{CO}_{2}$ is preferentially fixed into biomass. The recently reported increased ${ }^{12} \mathrm{C} /{ }^{13} \mathrm{C}$ ratio in the Isua chert is thus further evidence for widespread life $3.8 \mathrm{Gyr}$ ago (Shidlewski, 1988).

3.2.3. Biomolecular Clocks. By intercomparing base sequence homologies of nucleic acid molecules that are highly conserved through evolution, phylogenetic trees and divergence times of branches can be deduced, although the results are model-dependent (especially on the assumption of constancy of mutation rates over time). Analysis of the 5S rRNA subunit in different living organisms has dated the separation of the three "urkingdoms" (eubacteria, archaebacteria, and eukaryotes) as $2.3 \pm 0.2 \mathrm{Gyr}$ b.p. (Hori and Osawa, 1987). In a more recent analysis of tRNA sequences, Eigen et al. (1989) find that the genetic code "is not older than, but almost as old as our planet" (3.8 \pm 0.6 Gyr). Earlier, Carlin (1980) had dated the origin of mRNA, and possibly life, as $3.85 \pm 0.2$ Gyr ago, based on a relationship between species antiquity and the amount of poly-adenosine at the 3' end of their mRNAs, but his computation should be viewed with caution as it involves much inference and extrapolation on very small numbers. and 3.2 .

Figure 3 schematically summarizes the scenario for the origin of life presented in Secs. $\mathbf{3 . 1}$ 


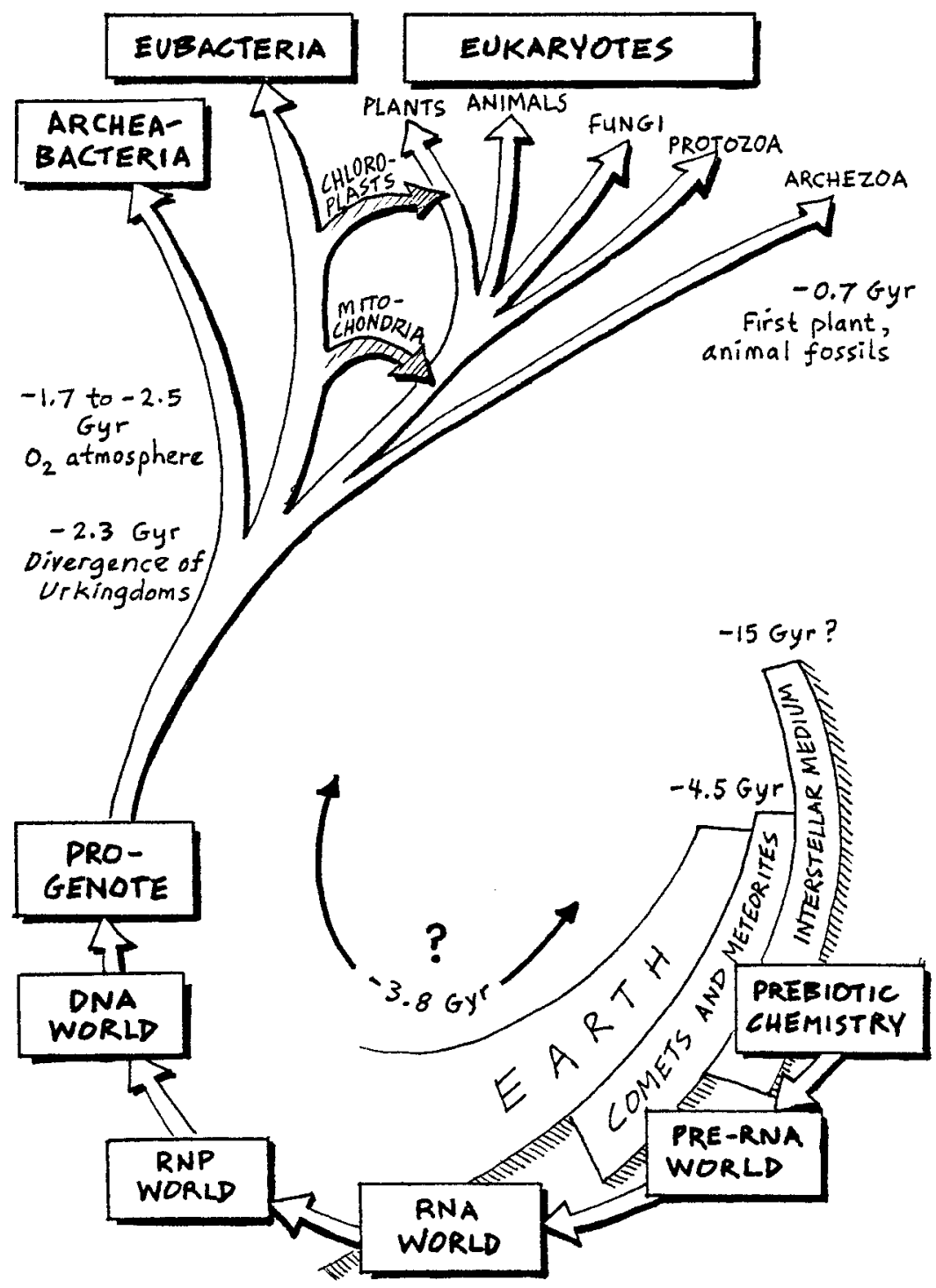

Figure 3. Scenario for the origin of life. Microorganisms were on the Earth at least 3.5 Gyr ago, and probably $3.8 \mathrm{Gyr}$ ago - almost as soon as it was physically possible after the end of the late heavy bombardment. Just what, biomolecularly, these organisms were at that time - RNA, RNP, DNA, or progenote - is uncertain. 


\section{Comets and Prebiotic Chemistry}

Given their rich organic composition, how might comets relate to the origin of life? On this question there has been intense speculation, ranging from emphasis on interstellar and terrestrial prebiotic chemistry (Clark, 1988; Delsemme, 1981, 1984; Greenberg, 1981; Ferris, 1988; Lazcano-Araujo and Oro, 1981; Oró and Berry, 1987; Ponnamperuma and Ochiai, 1982), which we consider in this section, to the claims of Hoyle and Wickramasinghe for fully fledged biosis and cometary panspermia, to be taken up in Sec. 5.2.

\subsection{COMETS AND LIFE: CARBON AND LIGHT ELEMENT ABUNDANCES}

Carbon is unique in the extent to which it forms highly stable single, double, and triple bonds with itself and other elements, giving rise to organic molecules with extraordinarily varied and complex structures. This property is central to life. As in comets, the majority of carbon in life is also in a highly complex, bonded form. Dissimilarly, however, the carbon network in living systems can tap energy gradients in its environment to create, expand, and perpetuate function and information content in the face of increasing universal entropy.

Halley's comet is $\approx 16 \%$ carbon by mass. By contrast, the Earth is carbon-depleted: only $\approx 0.1 \%$ of its crust is carbon, most of it in the form of carbonate and sedimentary organic matter such as kerogen. These total $9 \times 10^{22} \mathrm{~g}$ of carbon (Berner and Lasaga, 1989). Only $0.0007 \%$ of the Earth's crustal carbon mass is in living matter: it totals $5.6 \times 10^{17} \mathrm{~g}$. It is daunting to realize that this value is only one order of magnitude more than that of Halley's comet, and that there are a (roughly) estimated $10^{12}$ comets in the Oort cloud (Weissman, 1990b).

One circumstantial reason for looking to a comet-life connection is the uncanny correspondence of the abundances of their major volatile elements, pointed out by Delsemme (1981). Using his updated list of log abundances for Halley's comet (1990, Table 1, this volume), we derive the following atom-percent compositions, with the corresponding values for humans (Lehninger, 1982) given in parentheses: $\mathrm{H}, 55.2 \%(63.0 \%) ; \mathrm{C}, 11.0 \%(9.5 \%) ; \mathrm{N}, 2.4 \%(1.4 \%)$; and $\mathrm{O}, 27.6 \%$ (25.5\%). Hence, the bulk (>96 to $98 \%$ ) of both comets and man (who is close in composition to other organisms) is $\mathrm{C}, \mathrm{H}, \mathrm{O}$, and $\mathrm{N}$, and both largely consist of $\mathrm{H}_{2} \mathrm{O}$ (about $50 \%$ and $75 \%$, respectively).

\subsection{COMETS AND ORIGIN OF LIFE ON EARTH}

Because the Earth probably formed at hotter temperatures than previously realized, it must have degassed extensively, so that external sources are needed to account for its present volatiles (Delsemme, 1990, this volume). As comprehensively reviewed in this book (Bar-Nun and Owen, 1990; Delsemme, 1990) and elsewhere (Weissman, 1988), comets appear to fill the bill. Here we consider the chemical fates of the volatiles in impacting comets as they relate to terrestrial prebiotic chemistry.

\subsubsection{At the Very Least, Comets Supplied a Substantial Fraction of the Terrestrial Volatiles. With} the upward revision in the mass of the Oort cloud (Weissman, 1983; 1990b, this volume), estimates of cometary mass accreted by the Earth in the past 4.5 Gyr have also increased. We cite here only two recent estimates: $10^{24} \mathrm{~g}$ (with 0.4 ocean masses $\mathrm{H}_{2} \mathrm{O}$ ), if only $10 \%$ of impactors were comets (Chyba, 1987), and $3 \times 10^{24} \mathrm{~g}$, including 2 ocean masses $\mathrm{H}_{2} \mathrm{O}$ (Delsemme, 1990, this volume, inferred from Table 13). These are huge amounts which, assuming $16 \%$ carbon mass, clearly can account for the Earth's crustal carbon inventory (see above). Restricting consideration to only the Late Heavy Bombardment and subsequent period (4.0 Gyr to present), Ip and Fernandez (1988) estimate a $3 \times 10^{20} \mathrm{~g}$ accretion. Chyba (1990) has countered an objection 
(McKinnon, 1989) that large impactors might erode as much or more of the terrestrial volatile inventory as they deliver.

4.2.2. Impact Vaporization and Contribution to Prebiotic Chemistry. Here we assume that cometary organic chemicals are completely destroyed and metamorphosed by the shock and heat of Earth impact. Even so, $\mathrm{HCN}, \mathrm{H}_{2} \mathrm{CO}$, and other important prebiotic chemicals (Sec. 3.1.1) can be direct products of the impact, deriving from either the reprocessed primitive atmosphere or the impactor. For example, Fegley et al. (1986), modeling impacts on a variety of Earth atmospheres of differing pressures and $\mathrm{C} / \mathrm{H} / \mathrm{O} / \mathrm{N}$ proportions, find that significant amounts of $\mathrm{HCN}$, and lesser of $\mathrm{H}_{2} \mathrm{CO}$, are produced when the hot native gases recombine. While the $\mathrm{H}_{2} \mathrm{CO}$ quickly photolyzes in the atmosphere, $\mathrm{HCN}$ persists long enough to rain out to the surface; from the data of Fegley et al., we can infer a production of $5 \times 10^{21}$ to $23 \times 10^{21} \mathrm{~g} \mathrm{HCN}$ over $0.6 \mathrm{Gyr}$.

Inversely, the vaporized cometary material itself may recombine chemically. Using laser pulse heating of carbonaceous and ordinary chondrite meteorite samples to simulate the vaporization reactions, Muhkin et al. (1989) find that, compared with atmosphere reprocessing, $\mathrm{HCN}$ is produced just as effectively, and aldehyde and hydrocarbon, even more effectively. Overbeck et al. (1989a) propose that the hot impactor gases can recombine on cooling, nucleate on silica and clay catalyst particles lofted by the impact, photolyze and polymerize, and, after time, settle into the primeval ocean, where they dissolve as complex prebiotic compounds - a sort of "instant" primordial soup.

In all of these models, the production of significant prebiotic molecules is greater than in the old standard scheme that relies on UV and atmospheric spark discharge as chemical energy sources (Stribling and Miller, 1987). Moreover, these classical energy sources also work best in a highly reducing atmosphere, which was unlikely on the early Earth (Clark, 1988).

4.2.3. Some Cometary Organics May Have Survived Impact Chemically Intact. Prebiotic chemical evolution would have had a great head start if the complex organic chemicals in comets could have reached the Earth's surface. In the current conventional wisdom, however, little to nothing of something so fragile and volatile as a comet should survive impact with the Earth's atmosphere intact. Virtually nothing of the great Tunguska impactor - if indeed it was really a comet (Sekanina, 1983) - survived to reach the ground (Figure 4).

Clark (1988) has reviewed the problem of the chemical survival of cometary material impacting the atmosphere. Conceding the great difficulties in devising scenarios, he nevertheless envisages rare cases allowing for bulk survival of some cometary material, among them: a) grazing incidence encounters with the atmosphere; b) aeroshielding by a mechanically strong and/or thermally resistant processed mantle; c) explosion of the leading hemisphere with implosion, compression, and preservation of some of the opposite hemisphere; and d) exceptionally lowvelocity encounters with comets in improbable Earth-like orbits.

Greenberg (1987) maintains that the fluffy structure of comets "gives rise to the possibility that a large fraction of its submicron components of refractory organic material could be ablated during passage of the comet through the earth's atmosphere and float down to the surface preserving the organic component in its original form." While not crediting bulk survival of comets, Delsemme (1984), alluding to cometary interplanetary dust particles, writes that "the claimed destruction, by the heat of the collision with the earth, of all interstellar prebiotic molecules, is a false problem that does not stand the analysis of observations." Lazcano-Araujo and Oro (1981) project a minimal degradation of cometary organics in submicron particles, and many of the organics in larger particles could survive entry into the prebiological atmosphere, which lacked oxygen for pyrolysis. Citing such arguments, Ponnamperuma and Ochiai (1982) concur that some organic compounds could survive impact. 


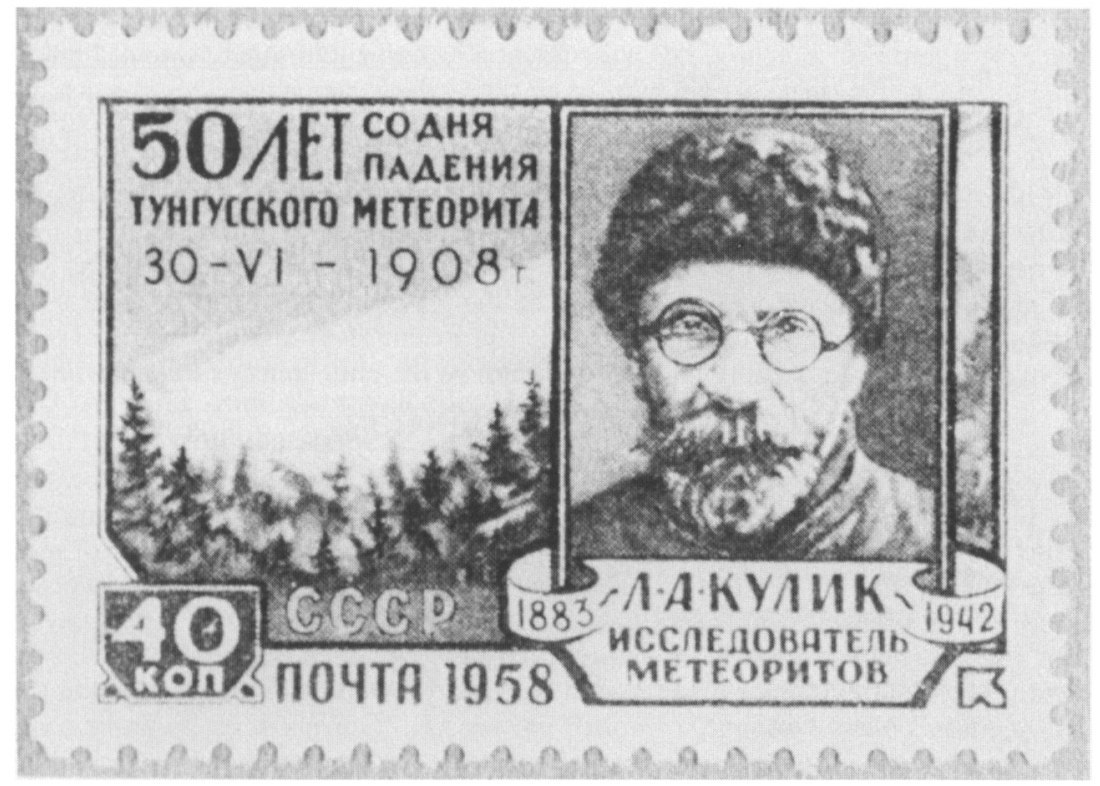

Figure 4. Depiction of the devastating atmospheric explosion near Tunguska, Siberia, on June 30, 1908 , thought to be due to the destruction of a meteor or small comet in the atmosphere. Soviet postage stamp commemorates the 50th anniversary of the event and honors the first investigator, L.A. Kulik.

The most definitive theoretical studies of the consequences of surface impact are by Melosh (1985), whose model predicts the survival of a small fraction of impactors as unshocked intact fragments. Indeed, such a model is necessary to explain the existence of the small carbonaceous chondrite fragments that were recovered from the Moon's surface (McSween, 1976). In their model, Thomas et al. (1989) obtain the survival of small fractions of comets after surface collisions, especially in the case of ocean impact. They also envisage aerobraking and ablation as mechanisms to maintain some cometary material intact.

4.2.4. Evidence From the K/T Boundary. The recent discovery of the extraterrestrial amino acid $\alpha$ amino isobutyric acid (AIB) near the Cretaceous-Tertiary (K/T) boundary layer (Zhao and Bada, 1989 ) is astonishing preliminary evidence for the large-scale chemical survival of a volatile impactor $65 \mathrm{Myr}$ ago. Based on an AIB/iridium ratio higher than that in the Murchison chondrite, these authors suggest that the impactor was a comet. The report will need confirmation (Cronin, 1989) and has recently been contested on the basis of xenon measurements (Anders, 1989). If it stands, however, its implications are considerable. Aside from providing further evidence for an extraterrestrial cause for the widespread $\mathrm{K} / \mathrm{T}$ species extinctions, the absolute amount of AIB deposited, $5 \times 10^{.5} \mathrm{~g} \cdot \mathrm{cm}^{-2}$ at the Stevns Klint site, is enormous. If [AIB] $=10^{-5} \mathrm{~g} \cdot \mathrm{cm}^{-2}$ is accepted as a more reasonable average global deposition density (since this site is known to be 
especially rich in iridium), we compute that $5 \times 10^{12} \mathrm{~g}$ of AIB in the parent impactor survived intact. If the parent body were a comet with a density $=0.6 \mathrm{~g} \cdot \mathrm{cm}^{-3}$ and a diameter $=12 \mathrm{~km}$, then its mass fraction of AIB would be $10^{-5}$, comparable to that of the Murchison (Cronin et al., 1979). Requiring a putative cometary AIB mass fraction to be tenfold higher would downsize the impactor to $5.5 \mathrm{~km}$, but the object would have to be significantly larger than this if much less than $100 \%$ of the AIB survived the collision.

4.2.5. A "Primeval Procreative Comet Pond?" If some bulk survival of infalling comets is accepted, what would be the chemical consequences? In a pioneering but little recognized paper, Chamberlin and Chamberlin (1908) postulated that preserved or vaporized carbonaceous components of impacting planetesimals could provide the grist for prebiological chemical evolution in early clay soils percolated by $\mathrm{H}_{2} \mathrm{O}$. Their prescient ideas on non-biological primordial synthesis of organic molecules leading to the appearance of life anticipated the classical organic ocean "soup" formulations of Oparin and Haldane (Lazcano-Araujo and Oro, 1981) nearly two decades later.

Oro's more specific proposition (1961) that cometary organics could deposit locally at impact sites, facilitating prebiological chemistry, has been brought to full flower by Clark (1988). A large portion of a comet, following a "soft landing," rapidly melts into a water lake of reactive organic compounds. $\mathrm{HCN}$ in the comet liquid could hydrolyze to formamide and formic acid or self-polymerize to form nucleic acid bases. Carbonic acid would convert grains into catalytic clay minerals and phyllosilicates. Dehydration and rehydration cycles at the "shoreline" would be associated with increasingly complex organic reactions, and prebiotic molecular evolution would also occur in the lake's "central mound" of wetted porous soil. Indigenous amphiphilic compounds would spontaneously form into membrane vesicles enclosing the evolving molecules, as observed with extracts of carbonaceous chondrites (Sec. 2.2.3; Figure 1). In this "primeval procreative comet pond," the origin of life is a highly localized event, the result of a single comet impact.

Krueger and Kissel (1989) envisage a hybrid scenario in which intact organic cometary grains sift onto an organic, Oparin-type "primordial soup" ocean, synergistically facilitating prebiotic chemical evolution toward life.

4.2.6. Impact Frustration of the Origin of Life. Life could not have arisen on Earth as long as the time scale for its origin exceeded the intervals between the environmentally devastating impacts in the Late Heavy Bombardment period. In this sense, comets are double-edged swords. Using an impactor flux derived from lunar and terrestrial cratering records, Maher and Stevenson (1988) deduce earliest possible origin times as 4.0 to $4.2 \mathrm{Gyr}$ ago (at deep marine hydrothermal vents), or 3.7 to $4.0 \mathrm{Gyr}$ (on the surface). Using similar arguments, Oberbeck and Fogelman (1989a) compute somewhat more recent dates, and Chyba (1990), somewhat more remote dates. Sleep et al. (1989) find these respective origin times as $3.8 \mathrm{Gyr}$ and $4.4 \mathrm{Gyr}$. All the values suggest that the times when life was first possible and first observed $(3.8 \mathrm{Gyr})$ are virtually identical, not separated by more than several hundred million years. Oberbeck and Fogelman (1989b) have even computed this maximum interval as $133 \mathrm{Myr}$ if life originated $3.5 \mathrm{Gyr}$ ago, but only $11 \mathrm{Myr}$ for the more likely origin time of $3.8 \mathrm{Gyr}$ ago.

\section{Origin of Life in Comets}

\subsection{LIQUID $\mathrm{H}_{2} \mathrm{O}$ CORES?}

An absolute requirement for life as we know it is the presence of liquid $\mathrm{H}_{2} \mathrm{O}$ (Kushner, 1981). Irvine et al. (1980) and Wallis (1980) proposed that this could be achieved by the short- 
lived radioisotope, ${ }^{26} \mathrm{Al}\left(\tau \approx 7.4 \times 10^{5} \mathrm{yr}\right.$, which could melt the icy interiors of comets of radius $\mathrm{r}>3$ to $6 \mathrm{~km}$ shortly after they formed. Liquid $\mathrm{H}_{2} \mathrm{O}$ cores in comets would then persist $10^{7} \mathrm{yr}$ for $r>10 \mathrm{~km}$, and $10^{9} \mathrm{yr}$ or longer for $\mathrm{r}>100 \mathrm{~km}$ (Irvine et al., 1980).

Is ${ }^{26} \mathrm{Al}$ a viable melting mechanism? Could chemical evolution lead to the origin of life in liquid comet cores?

5.1.1. Arguments Generally In Favor. The arguments generally in favor of chemical evolution leading to the origin of life in liquid comet cores are as follows:

a) There is no a priori reason biologically why not, given heat and chemical energy gradients.

b) Documented megacomets exist, including 2060 Chiron, $\mathrm{r} \approx 100 \mathrm{~km}$; possibly the Pluto/Charon system; and probably the great comets of 1577 and 1729.

c) There was a huge mass of potential prebiotic "broth." One unmelted comet of $\mathrm{r}=11 \mathrm{~km}$ and density $=0.6 \mathrm{~g} \cdot \mathrm{cm}^{-3}$ equals the Earth's current biomass. Weissman (1990a) currently estimates the Oort cloud mass very roughly as 100 $\mathrm{m}_{\text {Earth }}$, and earlier (1983) assigned $5.5 \%$ of its mass to comets brighter than $\mathrm{H}_{10}=$ 1.5 , which now would appear to correspond to $r \geq 10 \mathrm{~km}$. If $10 \%$ of the mass in this distribution were liquified, then the mass of "broth" stored at one time or another in the Oort cloud would be roughly $0.55 \mathrm{~m}_{\text {Earth }}$, which corresponds to $\approx$ $10^{9}$ biomasses!

d) Less dilution of prebiotic compounds would have occurred than that expected in the terrestrial ocean.

e) A very short time passed until the appearance of life on Earth (Sec. 3.3.4). Cometary panspermia (via scenarios in Sec. 4.2 ) would be an attractive explanation.

f) The heat conductivity of fluffy cometary material (Greenberg, 1987) is lower than the values assumed in the original models. This would lower the minimum radius required for liquid cores and extend the core lifetimes.

5.1.2. Arguments Generally Against. The arguments generally against chemical evolution leading to the origin of life in liquid comet cores are as follows:

a) No clear-cut evidence exists for an excess of ${ }^{26} \mathrm{Mg}$, the decay product of ${ }^{26} \mathrm{Al}$ (Jessberger and Kissel, 1987), consistent with Delsemme's (1982) earlier argument that the presence of calcium/aluminum-rich inclusions (CAI) in the Allende carbonaceous chondrite does not necessarily imply their existence in comets. On the other hand, Hutcheon and Hutchison (1989) recently identified excess ${ }^{26} \mathrm{Mg}$ in non-refractory chondritic material, implying that ${ }^{26} \mathrm{Al}$ was sufficiently widespread in the solar nebula to melt small chondritic planetesimals.

b) $\mathrm{P} /$ Halley's history is a cold one. The ortho/para $\mathrm{H}_{2} \mathrm{O}$ ratio measured in the comet (Mumma et al., 1987) suggests a cold temperature history, below $137 \mathrm{~K}$, the phase transition of amorphous to crystalline ice. From this, Prialnik et al. (1987) set an upper limit of initial ${ }^{26} \mathrm{Al}$ in comets as $10^{-2}$ that of CAI. They also argue that liquid cores could not exist with amorphous ice, as does Rickman (1990) in this volume.

c) The tensile strength is insufficient. Bar-Nun et al. (1981) and Donn (1982) argue that the vapor pressures of gases like $\mathrm{CO}_{2}$ and $\mathrm{CO}$ in liquid $\mathrm{H}_{2} \mathrm{O}$ would be too high to be contained by fragile cometary material, although the significantly lower $\mathrm{CO}_{2}$ and $\mathrm{CO}$ fractions now realized in P/Halley (Delsemme, 1990, this volume) would lower these pressures (but not necessarily militate against the argument). 
d) Low tensile strength aside, the nucleus as a fluffy, porous sieve would fail to prevent highly volatile species from leaking out during ${ }^{26} \mathrm{Al}$ heating. Thus the presence of $\mathrm{CO}$ in comets - assuming that at least some of it is parent - argues not only against liquid $\mathrm{H}_{2} \mathrm{O}$ cores, but crystalline ice as well (Rickman, 1990, this volume). Only amorphous $\mathrm{H}_{2} \mathrm{O}$ ice should be present.

e) Evidence exists against differentiation. Items a) and b), above, further bolster the good, if "circumstantial," arguments (Delsemme, 1982) favoring a homogenous composition for cometary nuclei. Even if comets are homogeneous, there is evidence that they at least evolve: among other examples, the Apollo objects may be "extinct" comets (Wetherill, 1979), "minor planet" 3200 Phaeton is orbitally associated with the Geminid meteors (IAU Circular 3881, 1983), and $1978 \mathrm{SB}$ is in an orbit similar to P/Encke (IAU Circular 3295, 1978) and may be a defunct fragment. While most explanations favor a choking off of activity by an accumulating mantle of non-volatile detritus, the possibility of wearing into a liquid $\mathrm{H}_{2} \mathrm{O}$-processed, less active core (Weissman, 1989b) must also be considered in aging comets.

f) ${ }^{26} \mathrm{Al}$ may be a double-edged sword. Bar-Nun et al. (1981) object that the $\gamma$ radiation from ${ }^{26} \mathrm{Al}$ would destroy biopolymers as quickly as they form; however, their argument ignores the persistence of liquid $\mathrm{H}_{2} \mathrm{O}$ after die-off of the isotope in the models.

5.1.3. Conclusion? As can be seen, the pro and con arguments for liquid $\mathrm{H}_{2} \mathrm{O}$ are diverse and complex; no effort is made to resolve them here. Further data and modeling are needed.

\subsection{COMETARY MICROORGANISMS AND PANSPERMIA}

The extremely short time now thought to be available for the origin of life on Earth (Sec. 3.2) is discomfitting and forces increased consideration of the idea that life is present on bodies other than Earth, and can be seeded on our planet by panspermia (Schidlowski, 1989), perhaps via meteorites or comets.

5.2.1. Meteoritic Microorganisms? Suggestions of a biological origin for material in carbonaceous chondrites came in the last century with the first recorded falls (reviewed in Urey, 1966). More recently, Claus and Nagy (1961), observing organized algae-like elements in Orgueil and Ivuna, ventured that they "may be microfossils indigenous to the meteorite," and no less than Harold Urey (1966) flatly concurred that hydrocarbons in carbonaceous chondrites were indigenous and "of biological origin." Pflug (1984b) interpreted the carbonaceous filaments he observed as possible products of metal grain catalysis, remaining neutral on the question of their potential biologic origin, while Hoyle (1984) claimed that Pflug "had detected the remains of life from outside earth."

5.2.2. Comet Viruses? In numerous books and papers, Hoyle and Wickramasinghe (see 1986 for references) extended the claim for extraterrestrial microorganisms to include comets. These sensationalist conjectures have generated much publicity and debate. Stemming largely from the close match of the infrared spectra of some biologic materials to those of astronomical sources, e.g., the 3- to 4- $\mu \mathrm{m}$ region of $\mathrm{P} /$ Halley (Hoyle and Wickramasinghe, 1987), they have been countered on grounds of non-specificity (e.g., Ponnamperuma and Ochiai, 1982; Campbell, 1983; Chyba and Sagan, 1987): any molecule containing $\mathrm{C}-\mathrm{H}$ bonds, biologic and nonbiologic, will emit at $3.4-\mu \mathrm{m}$ under suitable conditions. 
Hoyle and Wickramasinghe's claims that influenza and other epidemics have a random spread that cannot be explained conventionally - and therefore are seeded by infalling comet dust (e.g., Hoyle and Wickramasinghe, 1978) - are even more heterodox. These have been criticized from a statistical point of view (Senn, 1981). Biologically, Hoyle and Wickramasinghe (1979) passingly recognize, but then proceed to ignore, the fundamental property of viruses as obligate intracellular parasites, and the exquisite specificity of certain viruses, such as influenza, for special mammalian and bird hosts (which presumably do not exist in comets). Further, many viruses can penetrate their host cells only via highly discrete receptors. For example, most rhinoviruses, the major causes of the common cold, use the ICAM-1 cell surface molecule as their receptor (Greve et al., 1989; Staunton et al., 1989), and at that, only the ICAM-1 of humans, chimpanzees, and gibbons. Such restricted host-parasite specificity, at both the species and molecular level, implies such a high degree of interdependent coevolution (Agol, 1976) that a cometary connection is essentially unimaginable.

Henderson et al. (1989), who did try to imagine the possibility of a connection quantitatively, used evolutionary molecular sequence data on the $\mathrm{Hl}$ strains of influenza A virus, and a "minimal tree" mathematical model that most parsimoniously assigns evolutionary relationships among the various strains observed on Earth over time. They find that if the virus in the comet is assumed not to evolve, then the probability that it accounts for the observed terrestrial strains is 1 in $10^{66}$ ! If evolution on a comet is allowed, the chance increases to 1 in $10^{6}$, still virtually impossible.

Lost in these mathematical musings is the practical consideration that most viruses particularly influenza viruses - have long been known to be exquisitely sensitive to formaldehyde, which in small concentrations $(0.05 \%$ for influenza viruses: Chu, 1948) renders them non-infective. As we have seen (Sec. 2.3.3), comets contain substantial amounts of formaldehyde and its polymer, paraformaldehyde.

5.2.3. Infinitesimal Chance for the Origin of Life? We must accept cometary panspermia, according to Hoyle and Wickramasinghe (1981), because the chance for the indigenous origin of life on Earth is too small. They argue that with a minimum 10-amino-acid peptide sequence needed for catalysis, 20 available amino acids, and 2000 necessary enzymes, the chance of spontaneous assembly into a viable organism is an impossible $20^{-20,000}$.

This well-known argument has critical flaws not hitherto addressed. First, in the new paradigm, RNA preceded protein in the evolution of life. As noted in Sec. 3.1, RNA is not only a potentially self-replicating gene, but a catalyst requiring only short base sequences for activity. Second, complete assembly of RNA or protein need not be required to have happened all at once. Rather, complex enzymatic function likely evolved, through natural selection, as a patching together of multiple, simpler functions, carried as "minigenes" in the RNA world; these persist in the present DNA world as the multi-domain structure of proteins and their corresponding genes (Sec. 3.1.4). Third, there is high degeneracy between amino acid sequence on the one hand, and structure and function of the protein on the other. Gilbert (1987) roughly estimates the "universe" of possible enzyme structures as only $10^{5}$, much less than $20^{20,000}$. This former number renders the origin of life theoretically tractable. Indeed, if the latter is required, then the chance for the origin of life would not only be nil on Earth, but anywhere else in the universe as well (Ponnamperuma and Ochiai, 1982)! Lastly, the argument can be countered by the peculiar capacity for energy-importing, complex systems to undergo spontaneous self-organization - to proceed from randomness to order (Waldrop, 1990). The spontaneous formation of membranes (Figure 1) is but one example pertinent to the origin of life. Chemical evolution and selection of catalytic function, if currently hypothetical, would be another (Waldrop, 1990). 
5.2.4. Experimental Data. The VEGA 1 PUMA mass spectrometer provided some evidence against bulk quantities of microorganisms in Halley's comet: biologically mandated phosphorus (present in nucleotides), sodium, potassium, and sugars (via $\mathrm{CH}_{2} \mathrm{OH}^{+}$) were simply not observed in sufficient quantities in the VEGA 1 PUMA data (Kissel and Krueger, 1987).

On the other hand, these negative results should not be taken as evidence that comets could not be vehicles for panspermia (Arrhenius, 1903). The spores of Bacillus subtilis survive in vacuum and are extremely radiation resistant, particularly at very cold $(\approx 10 \mathrm{~K})$ temperatures. Weber and Greenberg (1985) experimentally estimate that these spores, if deposited in dense interstellar clouds, could accrete absorbing mantles and remain viable in the attenuated UV radiation fields for 4.5 to $45 \mathrm{Myr}$, enough time to transit from one solar system to another. Moreover, there is good reason to expect that Earth microorganisms can be spalled and lofted into interplanetary space after large meteor impacts and remain viable (Melosh, 1985). Hence, if microorganisms are ever isolated from comets, there will be a heavy burden of proof that they are not contaminants from Earth.

\section{Acknowledgments}

We thank Christopher Chyba and Paul Thomas, Laboratory for Planetary Studies, Cornell University; H. J. Melosh, Lunar and Planetary Laboratory, University of Arizona; John Cronin, Department of Chemistry, Arizona State University; David Deamer, Department of Zoology, University of California, Irvine; and Paul Weissman, Jet Propulsion Laboratory, Pasadena, California, for useful discussions. Chyba; Michael A'Hearn, University of Maryland; and David Seargent, The Entrance, New South Wales, provided helpful comments on the draft manuscript.

\section{References}

Agarwal, V.K., Schutte, W., Greenberg J.M., et al. (1986). Photochemical reactions in interstellar grains: Photolysis of $\mathrm{CO}, \mathrm{NH}_{3}$, and $\mathrm{H}_{2} \mathrm{O}$. Origins Life 16, 21-40.

Agol, V.I. (1976). An aspect of the origin and evolution of viruses. Origins Life 7, 119-132.

A'Hearn, M.F., Hoban, S., Birch, P.V., Bowers, C., Martin, R., and Klinglesmith, D.A. III (1986). Cyanogen jets in comet Halley. Nature 324, 649-651.

Allen, D.A., and Wickramasinghe, D.T. (1981). Diffuse interstellar absorption bands between 2.9 and 4.0 $\mu \mathrm{m}$. Nature 294, 239-240.

Amari, S., Anders, E., Virag, A., and Zinner, E. (1990). Interstellar graphite in meteorites. Nature 345, 238-240.

Anders, E. (1989). Pre-biotic organic matter from comets and asteroids. Nature 342, 255-257.

Arrhenius, S. (1903). In The Quest for Extraterrestrial Life, D. Goldsmith, ed., University Science Books, California, 1980, pp. 32-33 (transl. by D. Goldsmith from die Untschau 7, 481).

Bada, J.L., Cronin, J.R., Ho, M-S., et al. (1983). Reported optical activity of amino acids in the Murchison meteorite. Nature 301, 494-496.

Bar-Nun, A., Lazcano-Araujo, A, and Oró, J. (1981). Could life have evolved in cometary nuclei? Origins Life 11, 387-394.

Bell, M.B., Feldman, P.A., Kwok, S., and Matthews, H.E. (1982). Detection of $\mathrm{HC}_{11} \mathrm{~N}$ in IRC+10²16. Nature 295, 389-391.

Benner, S.A, Ellington, D.D., and Tauer, A. (1989). Modern metabolism as a palimpsest of the RNA world. Proc. Natl. Acad. Sci. U.S.A. 86, 7054-7058.

Bernath, P.F., Hinkle, K.H., and Keady, J.J. (1989). Detection of $\mathrm{C}_{5}$ in the circumstellar shell of IRC+10216. Science 244, 562-564. 
Berner, R.A., and Lasaga, A.C. (1989). Modeling the geochemical carbon cycle. Sci. Am. 260, 7481.

Bockelée-Morvan, D., Depois, D., Paubert, G., Colom, P., and Crovisier, J. (1990). Comet Austin (1989c1). I.A.U. Circular 5020.

Campbell, P. (1983). Infrared data debugged. Nature 306, 218-219.

Carlin, R.K. (1980). Poly(A): A new evolutionary probe. J. Theoret. Biol. 82, 353-362.

Cech, T.R. (1986a). RNA as an enzyme. Sci. Am. 255(5), 64-75.

Cech, T.R. (1986b). A model for the RNA-catalyzed replication of RNA. Proc. Natl. Acad. Sci. USA 83, 4360-4363.

Chamberlin, T.C., and Chamberlin, R.T. (1908). Early terrestrial conditions that may have favored organic synthesis. Science $28,897-911$.

Chu, C.M. (1948). Inactivation of haemagglutinin and infectivity of influenza and Newcastle disease viruses by heat and by formalin. J. Hygiene 46, 247-251.

Chyba, C. (1987). The cometary contribution to the oceans of primitive earth. Nature 330,632 635.

Chyba, C. (1990). Impact delivery and erosion of planetary oceans in the early inner Solar System. Nature 343, 129-133.

Chyba, C., and Sagan, C. (1987). Cometary organics but no evidence for bacteria. Nature 329, 208.

Chyba, C., and Sagan, C. (1989). The pre- and post-accretion irradiation history of cometary ice. In Interstellar Dust, A.G.G.M. Tielins, and L.J. Allamandola, eds., NASA Conference Publication 3036, pp. 433-435.

Clark, B.C. (1988). Primeval procreative comet pond. Origins Life 18, 209-238

Claus, G., and Nagy, B. (1961). A microbiological examination of some carbonaceous chondrites. Nature 192, 594-596.

Combes, M., Moroz, V.I., Crovisier, J., et al. (1988). The $2.5-\mu \mathrm{m}$ spectrum of comet Halley from the IKS-VEGA experiment. Icarus 76, 404-436.

Cosmovici, C.B., Schwarz, G., Ip, W-H., and Mack, P. (1988). Gas and dust jets in the inner coma of comet Halley. Nature 332, 705-709.

Crick, F.H.C. (1968). The origin of the genetic code. J. Mol. Biol. 38, 367-379.

Cronin, J.R. (1989). Amino acids and bolide impacts. Nature 339, 423-424.

Cronin, J.R., Pizzarello, S., and Cruikshank, D.P. (1988). Organic matter in carbonaceous chondrites, planetary satellites, asteroids and comets. In Meteorites and the Early Solar System, J.F. Kerridge, and M.S. Matthews, eds., University of Arizona Press, Tucson, pp. 819 857.

Cronin, J.R., Pizzarello, S., and Moore, C.B. (1979). Amino acids in an antarctic carbonaceous chondrite. Science 206, 335-337.

Deamer, D.W. (1985). Boundary structures are formed by organic components of the Murchison carbonaceous chondrite. Nature 317, 793-794.

Deamer, D.W., and Pashley, R.M. (1989). Amphiphilic components of the Murchison carbonaceous chondrite: Surface properties and membrane formation. Origins Life 19, 21-38.

Delsemme, A.H. (1981). Are comets connected to the origin of life? In Comets and the Origin of Life, C. Ponnamperuma, ed., D. Reidel Publ. Co., Dordrecht, Netherlands, pp. 141-159.

Delsemme, A. (1982). Chemical composition of cometary nuclei. In Comets, L.L. Wilkening, ed., University of Arizona Press, Tucson, pp. 85-130.

Delsemme, A.H. (1984). The cometary connection with prebiotic chemistry. Origins Life 14, 5160.

Delsemme, A.H. (1990). Organic compounds in comets: An astrophysical view. In Comets in the Post-Halley Era, R.L. Newburn, Jr., M. Neugebauer, and J. Rahe, eds., Kluwer Academic Publishers, Dordrecht, Netherlands, in press.

Donn, B. (1982). Comets: Chemistry and evolution. J. Mol. Evol. 18, 157-160 
Doudna, J.A., and Szostak, J.W. (1989). RNA-catalyzed synthesis of complementary-strand RNA. Nature 339, 519-522.

Eberhardt, P., Krankowski, D., Schulte, W., et al. (1987). The $\mathrm{CO}$ and $\mathrm{NH}_{2}$ abundance in comet P/Halley. Astronomy Astrophys. 187, 481-484.

Eigen, M., Lindemann, B., Tietze, M., Winkler-Oswatitsch, R., Dress, A., and von Haeseler, A. (1989). How old is the genetic code? Statistical geometry provides an answer. Science 244, 673-679.

Encrenaz, T., and Knacke, R. (1990). Carbonaceous compounds in comets. In Comets in the Post-Halley Era, R.L. Newburn, Jr., M. Neugebauer, and J. Rahe, eds., Kluwer Academic Publishers, Dordrecht, Netherlands, in press.

Epstein, S., Krishnamurphy, R.V., Cronin, J.R., Pizzarello, S., and Yuen, G.U. (1987). Unusual stable isotope ratios in amino acid and carboxylic acid extracts from the Murchison meteorite. Nature 326, 477-479.

Fegley, B., Jr., Prinn, R.G., Hartman, H., and Watkins, G.H. (1986). Chemical effects of large impacts on the earth's primitive atmosphere. Nature 319, 305-308.

Ferris, J.P. (1987). Prebiotic synthesis: Problems and challenges. Cold Spring Harbor Symp. Quant. Biol. 52, 29-35.

Ferris, J.P. (1988). Comet Halley - A good omen! Origins Life 18, 161-163.

Gilbert, W. (1987). The exon theory of genes. Cold Spring Harbor Symp. Quant. Biol. 52, 901905.

Greenberg, J.M. (1981). Chemical evolution of interstellar dust - A source of prebiotic material? In Comets and the Origin of Life, C. Ponnamperuma, ed., D. Reidel Publ. Co., Dordrecht, Netherlands, pp. 111-127.

Greenberg, J.M. (1982). What are comets made of? A model based on interstellar dust. In Comets, L.L. Wilkening, ed., University of Arizona Press, Tucson, pp. 131-163.

Greenberg, J.M. (1984). Chemical evolution in space. Origins Life 14, 25-36.

Greenberg, J.M. (1987). Comet Halley: A carrier of interstellar dust chemical evolution. Adv. Space Res. 7, 33-44.

Greenberg, J.M., Zhao, N., and Hage, J. (1989). Chemical evolution of interstellar dust, comets and the origin of life. Ann. Phys. Fr. 14, 103-131.

Greve, J.M., Davis, G., Meyer, A.M., et al., (1989). The major human rhinovirus receptor is ICAM-1. Cell 56, 839-847.

Henderson, I.M., Hendy, M.D., and Penny, D.J. (1989). Influenza viruses, comets and the science of evolutionary trees. J. Theoret. Biol. 140, 289-303.

Hori, H., and Ozawa, S. (1987). Origin and evolution of organisms as deduced from 5 S ribosomal RNA sequences. Mol. Biol. Evol. 4, 445-472.

Hoyle, F. (1984). The Intelligent Universe, Holt, Rinehart and Winston, New York.

Hoyle, F., and Wickramasinghe, N.C. (1977). Identification of the $2,200 \AA$ interstellar absorption feature. Nature 270, 323-324.

Hoyle, F., and Wickramasinghe, N.C. (1978). Influenza from space? New Scientist 79, 946-948.

Hoyle, F., and Wickramasinghe, C. (1979). Diseases From Space, Dent, London, pp. 152-154.

Hoyle, F., and Wickramasinghe, C. (1981). Comets - A vehicle for panspermia. In Comets and the Origin of Life, C. Ponnamperuma, ed., D. Reidel Publ. Co., Dordrecht, Holland, pp. 227239.

Hoyle, F., and Wickramasinghe, N.C. (1986). The case for life as a cosmic phenomenon. Nature 322, 509-511.

Hoyle, F., and Wickramasinghe, N.C. (1987). Organic dust in comet Halley. Nature 328, 117.

Hua, L-L., Kobayashi, K., Ochiai, E-I., Gehrke, C.W., Gerhardt, K.O., and Ponnamperuma, C. (1986). Identification and quantitation of nucleic acid bases in carbonaceous chondrites. Origins Life 16, 226-227, 1986.

Huebner, W.F. (1987). First polymer in space identified in comet Halley. Science 237, 628-630. 
Hutcheon, I.D., and Hutchison, R. (1989). Evidence from the Semarkona ordinary chondrite for ${ }^{26} \mathrm{Al}$ heating of small planets. Nature $377,238-241$.

Ip, W-H., and Fernandez, J.A. (1988). Exchange of condensed matter among the outer and terrestrial protoplanets and the effect of surface impact and atmospheric accretion. Icarus 74 , 47-61.

Irvine, W.M., and Hjalmarson, A. (1984). The chemical composition of interstellar molecular clouds. Origins Life 14, 15-23.

Irvine, W.M., Leschine, S.B., and Schloerb, F.P. (1980). Thermal history, chemical composition, and relationship of comets to the origin of life. Nature 283, 748-749.

Ivanov, C.P., Stoyanova, R.Z., and Mancheva, I.N. (1984). Some evidence for the possible presence of peptides in two chondrites by use of a sequencing procedure. Origins Life 14, 6168.

Jessberger, E. (1990). Chemical properties of cometary dust. In Comets in the Post-Halley Era, R.L. Newburn, Jr., M. Neugebauer, and J. Rahe, eds., Kluwer Academic Publishers, Dordrecht, Netherlands, in press.

Jessberger, E.K., and Kissel, J. (1987). Bits and pieces of Halley's comet. Lunar Planet. Sci. Conf. XVII, 466-467.

Johnstone, A., and Krankowsky, D. (1990). The composition of comets. In Comets in the PostHalley Era, R.L. Newburn, Jr., M. Neugebauer, and J. Rahe, eds., Kluwer Academic Publishers, Dordrecht, Netherlands, in press.

Joyce, G.F. (1987). Nonenzymatic template-directed synthesis of informational macromolecules. Cold Spring Harbor Symp. Quant. Biol. 52, 41-51.

Joyce, G.F., Schwartz, A.W., Miller, S.L., and Orgel, L.E. (1987). The case for an ancestral genetic system involving simple analogs of the nucleotides. Proc. Natl. Acad. Sci. USA 84, 4398-4402.

Joyce, G.F., Visser, G.M., van Boekel, C.A.A., van Boom, J.H., Orgel, L.E., and van Westrench, J. (1984). Chiral selection in poly(C)-directed synthesis of oligo(G). Nature 310, 602-604.

Kissel, J., and Krueger, F.R. (1987). The organic component in dust from comet Halley as measured by the PUMA mass spectrometer on board Vega 1 . Nature 326, 755-760.

Knoll, A.H., and Barghoorn, E.S. (1977). Archean microfossils showing cell division from the Swaziland system of South Africa. Science 198, 396-398.

Korth, A., Marconi, M.L., Mendis, D.A., et al. (1989). Probable detection of organic-dust-borne aromatic $\mathrm{C}_{3} \mathrm{H}_{3}{ }^{+}$ions in the coma of comet Halley. Nature 337, 53-55.

Krueger, F.R., and Kissel, J. (1989). Aspects of self-organization. Origins Life 19, 87-93.

Kushner, D. (1981). Extreme environments: Are there any limits to life? In Comets and the Origin of Life, C. Ponnamperuma, ed., D. Reidel Publ. Co., Dordrecht, Holland, pp. 241-248.

Langevin, Y., Kissel, J., Bertaux, J-L., and Chassefière, E. (1987). First statistical analysis of 5000 mass spectra of cometary grains obtained by PUMA (Vega 1) and PIA (Giotto) impact ionization mass spectrometers in the compressed modes. Astron. Astrophys. 187, 761-766.

Lazcano-Araujo, R., and Oro, J. (1981). Cometary material and the origins of life on earth. In Comets and the Origin of Life, C. Ponnamperuma, ed., D. Reidel Publ. Co., Dordrecht, Holland, 1981, pp. 191-225.

Lazcano, A., Guerroro, R., Margulis, L., and Oro, J. (1988). The evolutionary transition from RNA to DNA in early cells. J. Mol. Evol. 27, 283-290.

Leger, A, and Puget, J.L. (1984). Identification of the "unidentified" IR emission features of interstellar dust? Astron. Astrophys. 137, L5-L8.

Lehninger, A.L. (1982). Biochemistry, Worth Publishers, Inc., New York, p. 46.

Maher, K.A., and Stevenson, D.J. (1988). Impact frustration of the origin of life. Nature 331, 612-614.

Mar, A., and Oro, J. (1989). Synthesis of the coenzymes, ADPG, CDPG, and CDP-ethanolamine under primitive earth conditions. Origins Life 19, 254-255. 
McKinnon, W.B. (1989). Impacts giveth and impacts taketh away. Nature 338, 465-466.

McSween, H.Y. (1976). A new type of chondritic meteorite found in lunar soil. Earth Planet. Sci. Letters 31, 193-199.

Melosh, H.J. (1985). Ejection of rock fragments from planetary bodies. Geology 13, 144-148.

Miller, S.L. (1987). Which organic compounds would have occurred on the prebiotic earth? Cold Spring Harbor Symp. Quant. Biol. 52, 17-27.

Minn, K., and Greenberg, J.M. (1987). Formaldehyde absorption and visual extinction in the dark cloud L1709. Astron. Astrophys. 184, 315-321.

Mitchell, D.L., Lin, R.P., Anderson, K.A., et al. (1987). Evidence for chain molecules enriched in carbon, hydrogen, and oxygen in comet Halley. Science 237, 626-628.

Morowitz, H.J., Heinz, B., and Deamer, D.W. (1988). The chemical logic of a minimum protocell. Origins Life 18, 281-287.

Muhkin, L.M., Gerasimov, M.V., and Safonova, E.N. (1989). Origin of precursors of organic molecules during evaporation of meteorites and mafic terrestrial rocks. Nature 340, 46-48.

Mumma, M.J., Weaver, H.A., and Larson, H.P. (1987). The ortho-para ratio of water vapor in comet P/Halley. Astron. Astrophys. 187, 419-424.

Oberbeck, V.R., and Fogelman, G. (1989a). Impacts and the origin of life. Nature 339, 434.

Oberbeck, V.R., and Fogleman, G. (1989b). Estimates of the maximum time required to originate life. Origins Life 19,549-560.

Oberbeck, V.R., McKay, C.P., Scattergood, T.W., Carle, G.C., and Valentin, J.R. (1989). The role of cometary particle coalescence in chemical evolution. Origins Life 19, 39-55.

Orgel, L.E. (1968). The evolution of the genetic apparatus. J. Mol. Biol. 38, 381-393.

Orgel, L.E. (1987). Evolution of the genetic apparatus: A review. Cold Spring Harbor Symp. Quant. Biol. 52, 9-16.

Oro, J. (1961). Comets and the formation of biochemical compounds on the primitive earth. Nature 190, 389-390.

Oró, J., and Berry, J.M. (1987). Comets and life. Adv. Space Res. 7, 23-32.

Pflug, H.D. (1984a). Early geological record and the origin of life. Naturwiss. 71, 63-68.

Pflug, H.D. (1984b). Microvesicles in meteorites, a model of pre-biotic evolution. Naturwiss. 71, 531-532.

Ponnamperuma, C., and Ochiai, E. (1982). Comets and the origin of life. In Comets, L. Wilkening, ed., University of Arizona Press, Tucson, pp. 696-703.

Prialnik, D., Bar-Nun, A., and Podolak, M. (1987). Radiogenic heating of comets by ${ }^{26} \mathrm{Al}$ and implications for their time of formation. Astrophys. J. 319, 993-1002.

Rickman, H. (1990). The thermal history and structure of cometary nuclei. In Comets in the Post-Halley Era, R.L. Newburn, Jr., M. Neugebauer, and J. Rahe, eds., Kluwer Academic Publishers, Dordrecht, Netherlands, in press.

Robertson, D.L., and Joyce, G.F. (1990). Selection in vitro of an RNA enzyme that specifically cleaves single-stranded DNA. Nature 344, 467-468.

Sagan, C., and Khare, B.N. (1979). Tholins: Organic chemistry of interstellar grains and gas. Nature 277, 102-107.

Sekanina, Z. (1983). The Tunguska event: No cometary signature in evidence. Astron. J. 88, 1382-1414.

Senn, S.J. (1981). Can you really catch cold from a comet? New Scientist 92, 244-246.

Shapiro, R. (1988). Prebiotic ribose synthesis: A critical analysis. Origins Life 18, 71-86.

Shidlowski, M. (1988). A 3,800-million year isotopic record of life from carbon in sedimentary rocks. Nature 333, 313-318.

Shidlowski, M. (1989). Initiation of life processes on the early earth: A case for panspermia? Origins Life 19, 454-455. 
Shock, E.L., and Schulte, M.D. (1990). Amino acid synthesis in carbonaceous meteorites by aqueous alteration of polycyclic aromatic hydrocarbons. Nature 343, 728-731.

Sleep, N.H., Sahnle, K.J., Kasting, J.F., and Morowitz, H.J. (1989). Annihilation of ecosystems by large asteroid impacts on the early Earth. Nature 342, 139-142.

Snyder, L.E., Hollis, J.M., Svenram, R.D., Lovas, F.J., Brown, L.W., and Buhl, D. (1983). An extensive search for conformer II glycine. Astrophys. J. 268, 123-128.

Staunton, D.E., Merluzzi, V.J., Rothlein, R., Barton, R., Marlin, S.D., and Springer, T.A. (1989). A cell adhesion molecule, ICAM-1, is the major surface receptor for rhinovirus. Cell 56, 849853.

Strazzulla, G., Calcagno, L., and Foti, G. (1983). Mon. Not. R. Astron. Soc. 204, 59p-62p.

Strazzula, G., and Johnson, R.E. (1990). Irradiation effects on comets and cometary debris. In Comets in the Post-Halley Era, R.L. Newburn, Jr., M. Neugebauer, and J. Rahe, eds., Kluwer Academic Publishers, Dordrecht, Netherlands, in press.

Stribling, R., and Miller, S.L. (1987). Energy yields for hydrogen cyanide and formaldehyde synthesis: The HCN and amino acid concentrations in the primitive ocean. Origins Life 17, 261-273.

Thomas, P.J., Chyba, C.F., Brookshaw, L., and Sagan, C. (1989). Impact delivery of organic molecules to the early earth and implications for the terrestrial origin of life. Lunar Planet. Sci. Conf. XX, 1117-1118.

Urey, H.C. (1966). Biological material in meteorites: A review. Science 151, 157-166.

Waldrop, M.M. (1989). Catalytic RNA wins the chemistry Nobel. Science 246, 325.

Waldrop, M.M. (1990). Spontaneous order, evolution, and life. Science 247, 1543.

Walker, J.C.G., Klein, C., Shidlowski, M., Schopf, J.W., Stevenson, D.J., and Walter, M.R. (1983). In Earth's Earliest Biosphere: Its Origin and Evolution, J. Schopf., ed., Princeton University Press, Princeton, New Jersey, pp. 260-290.

Wallis, M.K. (1980). Radiogenic melting of primordial comet interiors. Nature 284, 431-433.

Wdowiak, T.J., Flickinger, G.C., and Cronin J.R. (1989). Insoluable organic material of the Orgueil carbonaceous chondrite and the unidentified infrared bands. Astrophys. J. 328, L75L79.

Weber, A.L. (1989). Glyceraldehyde as a source of energy and matter for the origin of life. Origins Life 19, 317-318.

Weber, P., and Greenberg, J.M. (1985). Can spores survive in interstellar space? Nature 316, 403407.

Weiner, A.M. (1987). The origins of life. In Molecular Biology of the Gene, 4th. ed., J.D. Watson, et al., eds., The Benjamins/Cummings Publ. Co., Inc., Menlo Park, California, pp. 1098-1163.

Weissman, P.R. (1983). The mass of the Oort cloud. Astron. Astrophys. 118, 90-95.

Weissman, P.R. (1988). The impact history of the solar system: Implications for the origin of atmospheres. In Origin and Evolution of Planetary and Satellite Atmospheres, S.K. Atreya, et al., eds., University of Arizona Press, Tucson, pp. 230-267.

Weissman, P.R. (1989). Physical processing of cometary nuclei since their formation. In Comet Halley 1986: Worldwide Investigations, Results and Interpretations, P. Moore, and J. Mason, eds., Ellis Horwood Ltd., Chichester, U.K., in press.

Weissman, P.R. (1990a). The Oort Cloud. Nature 344, 825-830.

Weissman, P.R. (1990b). Dynamical history of the Oort cloud. In Comets in the Post-Halley Era, R.L. Newburn, Jr., M. Neugebauer, and J. Rahe, eds., Kluwer Academic Publishers, Dordrecht, Netherlands, in press.

Wetherill, G.W. (1979). Apollo objects. Sci. Am. 240, 54-65.

Wickramasinghe, D.T., and Allen, D.A. (1980). The 3.4- $\mu \mathrm{m}$ interstellar absorption feature. Nature 287, 518-519.

Woese, C.R. (1967). The origin of the genetic code. Harper and Row, New York, p. 193. 
Woese, C.R. (1987). Bacterial evolution. Microbiol. Rev. 51, 221-271.

Zhao, M., and Bada, J.L. (1989). Extraterrestrial amino acids in Cretaceous/Tertiary boundary sediments at Stevns Klint, Denmark. Nature 339, 463-465. 